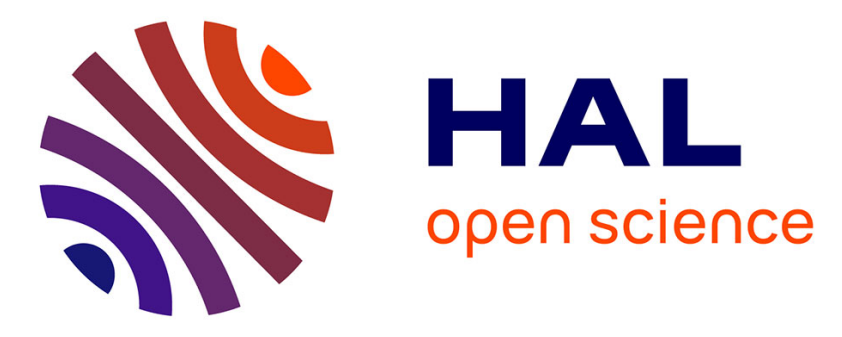

\title{
Critical boron-doping levels for generation of dislocations in synthetic diamond
}

\author{
M.-P. Alegre, D. Araujo, Alexandre Fiori, J.-C. Pinero, F Lloret, M.P. Villar, \\ Philipp Achatz, Gauthier Chicot, Etienne Bustarret, F Jomard
}

\section{- To cite this version:}

M.-P. Alegre, D. Araujo, Alexandre Fiori, J.-C. Pinero, F Lloret, et al.. Critical boron-doping levels for generation of dislocations in synthetic diamond. Applied Physics Letters, 2014, 105 (17), pp.173103. 10.1063/1.4900741 . hal-01079903

\section{HAL Id: hal-01079903 https://hal.science/hal-01079903}

Submitted on 4 Nov 2014

HAL is a multi-disciplinary open access archive for the deposit and dissemination of scientific research documents, whether they are published or not. The documents may come from teaching and research institutions in France or abroad, or from public or private research centers.
L'archive ouverte pluridisciplinaire HAL, est destinée au dépôt et à la diffusion de documents scientifiques de niveau recherche, publiés ou non, émanant des établissements d'enseignement et de recherche français ou étrangers, des laboratoires publics ou privés. 


\title{
Critical boron-doping levels for generation of dislocations in synthetic diamond
}

\author{
M. P. Alegre, ${ }^{1, a)}$ D. Araújo, ${ }^{1}$ A. Fiori, ${ }^{2}$ J. C. Pinero, ${ }^{1}$ F. Lloret, ${ }^{1}$ M. P. Villar, ${ }^{1}$ P. Achatz, ${ }^{2}$ \\ G. Chicot, ${ }^{2}$ E. Bustarret, ${ }^{2}$ and F. Jomard ${ }^{3}$ \\ ${ }^{1}$ Departamento de Ciencias de los Materiales e Ingeniería Metalúrgica y Química, Universidad de Cádiz, \\ 11510 Puerto Real, Cádiz, Spain \\ ${ }^{2}$ Université Grenoble Alpes, Institut NEEL, 25 av. des Martyrs, 38042 Grenoble, France \\ ${ }^{3} \mathrm{GEMaC}, \mathrm{CNRS}$ and Université de Versailles St Quentin, 45 Avenue des États-Unis, 78035 Versailles, France
}

(Received 9 July 2014; accepted 4 October 2014; published online 28 October 2014)

\begin{abstract}
Defects induced by boron doping in diamond layers were studied by transmission electron microscopy. The existence of a critical boron doping level above which defects are generated is reported. This level is found to be dependent on the $\mathrm{CH}_{4} / \mathrm{H}_{2}$ molar ratios and on growth directions The critical boron concentration lied in the $6.5-17.0 \times 10^{20} \mathrm{at} / \mathrm{cm}^{3}$ range in the $\langle 111\rangle$ direction and at $3.2 \times 10^{21} \mathrm{at} / \mathrm{cm}^{3}$ for the $\langle 001\rangle$ one. Strain related effects induced by the doping are shown not to be responsible. From the location of dislocations and their Burger vectors, a model is proposed, together with their generation mechanism. (C) 2014 AIP Publishing LLC.

[http://dx.doi.org/10.1063/1.4900741]
\end{abstract}

Natural diamonds, grown under thermodynamically stable conditions, generally have a very low density of crystalline defects, but these have an intense impact on their optical, thermal, and electronic properties. ${ }^{1,2}$ The literature describing several structural defects is often based on Raman spectroscopy, ${ }^{3}$ X-ray diffraction, ${ }^{4}$ and cathodoluminescence ${ }^{5}$ techniques. More rarely, transmission electron microscopy (TEM) has been employed, ${ }^{6-12}$ due to the remarkable hardness of diamond, which makes the specimen preparation more difficult. Understanding the origin of defects in diamond, and classifying them according to their type and spatial distribution, is an indispensable step toward a better control of the microstructure and properties of synthetic diamond films. Synthetic diamond is one of the most promising material for high power devices due to its extraordinary physical properties, such as high thermal conductivity $(22 \mathrm{~W} / \mathrm{cm} \mathrm{K})$, electric breakdown field $(>10 \mathrm{MV} / \mathrm{cm})$, and carrier mobility $\left(\mu_{n}=1000 \mathrm{~cm}^{2} / \mathrm{Vs}, \mu_{p}=2000 \mathrm{~cm}^{2} / \mathrm{Vs}\right){ }^{13,14}$ In order to improve its electrical conduction, dopants are added during the synthetic diamond growth. In particular cases, metallic diamond layers are necessary, ${ }^{15-17}$ which may be the case if the boron concentration is high enough ${ }^{16}$ ([B] $\geq 5 \times 10^{20} \mathrm{at} / \mathrm{cm}^{3}$ ). Despite the quantity of studies by different techniques focused on dislocations observed in the epilayers but originated from diamond substrates, only a few mentions the presence of additional planar and onedimensional defects, i.e., stacking faults, twins, and dislocations brought about by homoepitaxial overgrowths and boron doping. ${ }^{18-20}$

In this work, conventional TEM (diffraction contrast mode, CTEM) was used to determine a relationship between doping level and the generation of such extended defects. The latter behavior is evaluated versus crystalline orientation, boron concentration, and film thickness to establish rules to prevent the generation of such defects. This study

\footnotetext{
${ }^{a)}$ E-mail: maripaz.alegre@uca.es
}

aims at predicting the maximum doping level for a defectfree epitaxy, depending on the growing conditions.

Three sets of samples have been compared: $\langle 111\rangle$ single $\mathrm{p}^{+}$layers (samples $\mathrm{A}, \mathrm{B}, \mathrm{C}$ ), $\langle 001\rangle$ thick single $\mathrm{p}^{+}$layers (samples D, E), and $\langle 001\rangle$ thin $\mathrm{p}^{+}$layers arranged in $\mathrm{p}^{+} / \mathrm{p}^{-}$ multilayer stacks (samples F-16, F-26, and F-27). Diamond films were grown on Ib-type HPHT substrates from Sumitomo Electric on $\langle 111\rangle$ and $\langle 001\rangle$ orientations, respectively. A chemical cleaning process was carried out to remove the superficial contamination including non-diamond carbon phases, before growth. Prolonged $0.3-2 \mathrm{~h} \mathrm{H}_{2}$ plasma has been applied to eliminate residual contamination and to etch away the damaged surface layer resulting from the substrate polishing. Diamond growths were performed in a NIRIM-type Microwave Plasma Chemical Vapor Deposition (MPCVD) reactor, ${ }^{21}$ under 50 Torr. Growth parameters were adjusted to achieve high boron doping levels. Secondary Ion Mass Spectroscopy (SIMS) provided a dopant depth profile for each sample, being the resultant average boron concentrations presented in Table I.

The specimens for cross sectional TEM observations were obtained in a FIB apparatus (Focused Ion Beam-Dual Beam Quanta 200) following a lift-out method. ${ }^{22,23}$ All cross section lamellas were extracted from the center of the sample, i.e., the most homogeneous area, with thicknesses around $200 \mathrm{~nm}$. Diffraction contrast observations were performed with a Jeol 1200EX and a Jeol 2010F microscopes operating at $120 \mathrm{keV}$ and $200 \mathrm{keV}$, respectively. Observations were carried out under dark field (DF) conditions at 004, 220, and 111 reflections ( $g$ vector).

Fig. 1 shows DF observations of a $0.34 \mu$ m-thick $p^{+}$ layer grown along $\langle 111\rangle$ direction (sample A) recorded at the [110] pole ( $g=004$ and $g=111$ reflections). The combination of these observations revealed the type of dislocation, their associated peculiar location and some planar defects. In the case of $\boldsymbol{g}=004$ (Fig. 1(a)), arrows 1, 2, and 3 indicate some of the threading dislocations which are not visible for 
TABLE I. Summary of growth parameters, layer thickness, boron doping level, and generated dislocation for all p $\mathrm{p}^{+}$layers studied.

\begin{tabular}{|c|c|c|c|c|c|c|c|c|}
\hline $\begin{array}{l}\text { Layer } \\
\text { label }\end{array}$ & $\begin{array}{l}\text { Sample } \\
\text { name }\end{array}$ & $\begin{array}{c}\text { Layer } \\
\text { position }^{\mathrm{a}}\end{array}$ & $\begin{array}{l}\text { Growth } \\
\text { direction }\end{array}$ & $\begin{array}{c}\mathrm{CH}_{4} / \mathrm{H}_{2} \\
(\%)\end{array}$ & $\begin{array}{l}\mathrm{B} / \mathrm{C}_{\mathrm{gas}} \\
(\mathrm{ppm})\end{array}$ & $\begin{array}{c}\text { Thickness }^{\mathrm{b}} \\
\text { (nm) }\end{array}$ & $\begin{array}{c}{[\mathrm{B}]_{\text {solid }}{ }^{\mathrm{b}}} \\
\left(\times 10^{20} \mathrm{at} / \mathrm{cm}^{3}\right)\end{array}$ & $\begin{array}{l}\text { Dislocation density } \\
\qquad\left(\times 10^{9} \mathrm{~cm}^{-2}\right)\end{array}$ \\
\hline A & PA01 & $\mathrm{n} / \mathrm{a}$ & 111 & 0.15 & 6000 & $\sim 340$ & $\sim 18$ & $\sim 2$ \\
\hline B & PA20 & $\mathrm{n} / \mathrm{a}$ & 111 & 0.6 & 500 & $\sim 350$ & 4.5 & $\ldots$ \\
\hline $\mathrm{C}$ & PA31 & $\mathrm{n} / \mathrm{a}$ & 111 & 0.6 & 1000 & $\sim 450$ & $\sim 10$ & $\sim 32$ \\
\hline D & PA14 & $\mathrm{n} / \mathrm{a}$ & 100 & 4 & 1800 & $\sim 3700$ & $\sim 13$ & $\ldots$ \\
\hline $\mathrm{E}$ & PA23 & $\mathrm{n} / \mathrm{a}$ & 100 & 4 & 2500 & $\sim 2000$ & 45 & $>100^{c}$ \\
\hline F-27.1 & ML27 & 1 & 100 & 0.5 & 100 & 23 & 0.3 & $\ldots$ \\
\hline F-27.2 & ML27 & 2 & 100 & 0.5 & 300 & 24 & 1 & $\ldots$ \\
\hline F-27.3 & ML27 & 3 & 100 & 0.5 & 800 & 25 & 2.5 & $\ldots$ \\
\hline F-27.4 & ML27 & 4 & 100 & 0.5 & 2000 & 20 & $\sim 5$ & $\ldots$ \\
\hline F-27.5 & ML27 & 5 & 100 & 0.5 & 6000 & 14 & 11 & $\ldots$ \\
\hline F-26.1 & ML26 & 1 & 100 & 0.5 & 6000 & 14 & 14 & $\ldots$ \\
\hline F-16.4 & ML16 & 4 & 100 & 0.5 & 6000 & 6 & 20 & $\ldots$ \\
\hline F-16.3 & ML16 & 3 & 100 & 0.5 & 6000 & 12 & 28 & $\ldots$ \\
\hline F-16.2 & ML16 & 2 & 100 & 0.5 & 6000 & 11 & 28 & $\ldots$ \\
\hline F-16.1 & ML16 & 1 & 100 & 0.5 & 6000 & 9 & 37 & $>100^{c}$ \\
\hline
\end{tabular}

${ }^{\mathrm{a}}$ Corresponds to the $\mathrm{p}^{+}$layer position in the multilayer stack.

${ }^{\mathrm{b}}$ Measured by SIMS.

${ }^{\mathrm{c}}$ Not possible to distinguish individual dislocations over $10^{11}$ dislocation $/ \mathrm{cm}^{2}$.

$\boldsymbol{g}=111$ (Fig. 1(b)). Invisibility conditions of dislocations were reached only for $g=111$. Then, according to the invisibility criterion $\boldsymbol{g} . \boldsymbol{b}=\mathbf{0}$, the Burger vector $(\boldsymbol{b})$ could be either $1 / 2[01 \overline{1}]$ or $1 / 6[11 \overline{2}]$, as already reported in diamond. ${ }^{6}$ As highlighted in Fig. 1(a) by arrows 4 and 5, misfit dislocations lying parallel to the surface were observed as dots (or spots) in the micrographs. They were found at different positions within the $\mathrm{p}^{+}$layer thickness. Such behavior is commonly observed inside thick gradual composition layers, such as $\mathrm{In}_{\mathrm{x}} \mathrm{Ga}_{1-\mathrm{x}} \mathrm{As} / \mathrm{GaAs}$, whose composition varies in the film thickness. $^{24}$ However, such a phenomenon has not been reported in the case of a nominally constant composition layer. Usually, dislocations coming from interfacial effects or lattice mismatch are located at the interface between an active layer and its buffer, ${ }^{20}$ here at the $\mathrm{p}^{+} / \mathrm{p}^{-}$interface. Moreover, in such situations, the number of threading dislocations is lower than the misfit dislocations one. Thus, the dislocation behavior observed here in boron-doped diamond is unusual inasmuch not any interaction between misfit-like dislocations (M-L) were observed to generate threading dislocations (TH).

The introduction of substitutional boron into diamond leads to an expansion $(\delta \mathrm{a} / \mathrm{a})$ of the lattice parameter due to larger covalent radius of boron $\left(r_{B}=0.088 \mathrm{~nm}\right)$ compared to that of carbon $\left(\mathrm{r}_{\mathrm{C}}=0.077 \mathrm{~nm}\right) ;{ }^{25-28}$ for the maximum $\mathrm{B}$ concentration achieved $\left(\approx 7 \times 10^{21} \mathrm{at} / \mathrm{cm}^{3}\right)$, the shift of the lattice parameter is about $0.3 \%$ (or $0.011 \AA$ ). ${ }^{27}$ In the case of an isostatic stress, strain is $\delta a / a_{\text {epilayer }}$. Here, it is assumed that all (i) epilayers are grown coherently on the substrate, i.e., (pseudomorphic growth) without misfit dislocations and (ii) epilayers are much thinner than the substrate, so that strain in the substrates can be neglected. The films will be then under compression strain in the in-plane growth $\left(\varepsilon^{\prime \prime}\right)$ and under extension strain perpendicularly $\left(\varepsilon^{\perp}\right)$. From an energetical point of view and taking into account the strongly anisotropic elasticity of diamond, one gets for total strain of the layer

$$
\begin{aligned}
\varepsilon & =\frac{\delta a}{a_{\text {epi }}} \approx \frac{\delta a}{a_{\text {sub }}}=\gamma_{h k l} \frac{\delta a^{\perp}}{a_{\text {sub }}} \\
& =\gamma_{\text {hkl }}\left[\beta_{\text {size }} n_{B}+\beta_{\text {pair }} n_{B B}+\beta_{\text {electro }} n_{B^{-}}\right] .
\end{aligned}
$$

Indeed, only $a^{\perp}$ can be known experimentally versus boron doping. The $\gamma_{h k l}$ parameter is related to the elastic constants and allows relating the in-plane strain $\left(\varepsilon^{\prime \prime}\right)$ to the perpendicular strain $\left(\varepsilon^{\perp}\right)$. Its behavior varies with the growth orientation: $\gamma_{111}=\left(c_{11}+2 / 3 C\right) /\left(c_{11}+2 c_{12}\right)$ and $\gamma_{100}=\left(c_{11} / c_{11}-2 c_{12}\right)$, where $c_{11}, c_{12}$, and $c_{44}$ are the elastic constants and $C=c_{44}-c_{11}+c_{12}$. In the case of diamond, ${ }^{29} \gamma_{100}=0.8113$ and $\gamma_{111}=0.9136$. Thus, for an identical doping level, the
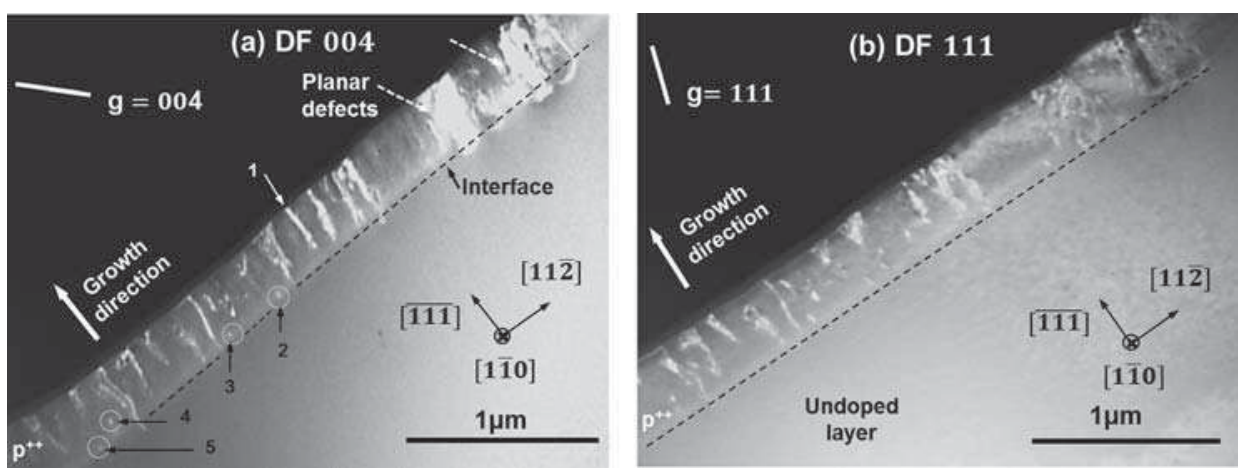

FIG. 1. Dark field XTEM micrographs of the sample A recorded at (a) $\mathrm{g}=004$ and (b) $\mathrm{g}=111$ reflections. Dashed lines correspond to the interface between $\mathrm{p}^{+}$and $\mathrm{p}^{-}$layers. Solid and dashed arrows denote threading dislocations and bi-dimensional defects, respectively. Arrows 1, 2, 3, 4, and 5 show threading dislocations exclusively visible under the $\mathrm{g}=004$ reflection. 
lattice expansion changes with the crystalline growth orientation. The variation of the lattice parameter with the boron concentration depends also on the boron pair formation ${ }^{30,32}$ and on the electrostatic interaction when dopant atoms are ionized, ${ }^{29-31}$ as introduced in the 2 nd and 3 rd term of Eq. (1). The values of the $\beta i$ here used here are: $\beta_{\text {size }}=8.12 \times 10^{-25} \mathrm{~cm}^{3}$, $\beta_{\text {pair }}=12.4 \times 10^{-25} \mathrm{~cm}^{3}, \beta_{\text {electro }}=-2.74 \times 10^{-25} \mathrm{~cm}^{3}$, taken from literature. ${ }^{26,28}$ Boron concentration into diamond lattice is represented by $n_{B} ; n_{B B}$ is the density of $\mathrm{B}_{2}$ pairs; and $n_{B}{ }^{-}$is the concentration of ionized boron.

To have a rough estimation of the thickness (critical lattice thickness, CLT) necessary to generate dislocations, i.e., when the strain energy is comparable to the dislocations energy, the Matthews Blakeslee model is here used. The calculated CLT for a boron doping level of $10^{21} \mathrm{at} / \mathrm{cm}^{3}$ (i.e., a strain around $\left.6 \times 10^{-4}\right)^{26}$ stands around a few tens of $\mu \mathrm{m}$ $(28 \mu \mathrm{m}),{ }^{19}$ introducing the Eq. (1) into the MB equation. ${ }^{33-35}$ Such CLT is about two orders of magnitude larger than the total thickness of the observed layer, which is $0.34 \mu \mathrm{m}$.

To definitively discard MB mechanism, very thin (6-12 nm) layers with very high doping level were grown. Fig. 2 shows a DF micrograph of sample F-16 recorded in the $\left[001^{-}\right]$zone axis. This sample grown along $\langle 001\rangle$ is composed of four $\mathrm{p}^{+}$layers (labeled from F-16.1 to F-16.4) separated by $\mathrm{p}^{-}$layers, where the boron concentration was kept below $10^{16} \mathrm{at} / \mathrm{cm}^{3}$. The grey contrast between $\mathrm{p}^{+}$and $\mathrm{p}^{-}$layers has a chemical origin, and it is used to quantify the boron enrichment ${ }^{36}$ above $10^{20} \mathrm{at} / \mathrm{cm}^{3}$. This chemical contrast coexists with the contrast induced by dislocations in the present DF configuration. The thickness of $\mathrm{p}^{+}$layers did not play an important role in the defect generation. Indeed, most of threading dislocations were generated at the first $\mathrm{p}^{+} / \mathrm{p}^{-}$interface. Dislocations loops stopped their propagation inside the $\mathrm{p}^{-}$ layer located between the first and second $\mathrm{p}^{+}$layer (dotted line in Fig. 2), and a few still were observed up to the fourth $\mathrm{p}^{+}$layer. Also, some dislocations are observed to recombine with each other (dashed ellipses in Fig. 2). Another remarkable

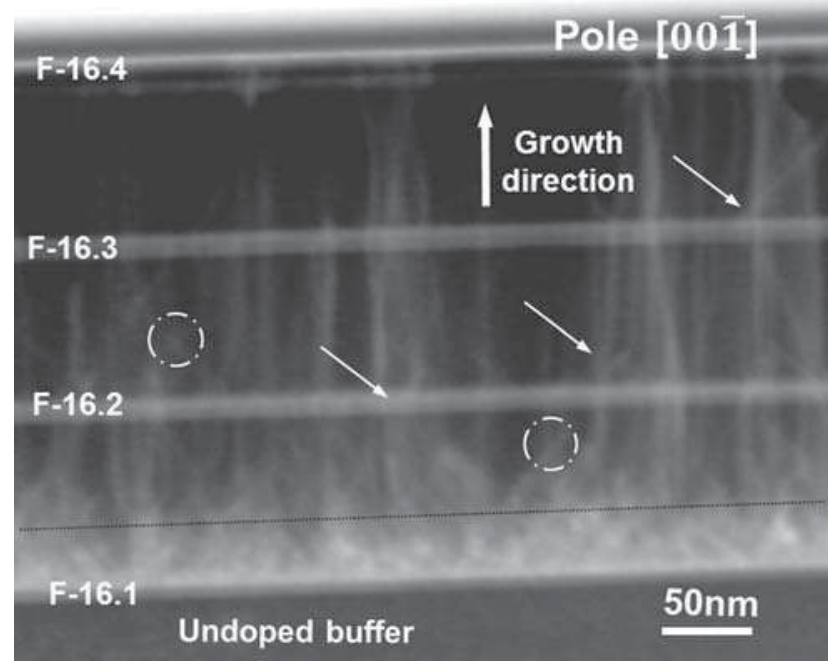

FIG. 2. TEM micrographs recorded at $[00 \overline{1}]$ axis zone of the sample F-16. Arrows denote changes in the propagation direction of dislocations across the diamond layers. The dotted line bounds the region where the most of dislocations disappear. Dashed circles frame indicates convergence points between dislocations. feature is their direction of propagation, which is changing when crossing a $\mathrm{p}^{+}$layer (see arrows). Thin $\mathrm{p}^{+}$layers can act as barriers to dislocations propagation, because the high boron concentration increases the probability that a dislocation meets an interstitial or a boron pair on its way, and stops its extension during crystal growth. Epilayers grown under $\langle 100\rangle$ directions in this reactor are usually fully strained ${ }^{37}$ up to tens of micrometers thickness ${ }^{38}$ and free of dislocations ${ }^{36}$ (except for those from the substrate), similar to sample D.

If the accumulated strain energy is not the driving force other key parameters have to be considered such as the boron density, the interface roughness or some growth conditions. Another mechanism based on in-plane phenomena during growth must be considered. Indeed, dislocations are observed to be generated at all possible epilayer depth. In fact, the first $\mathrm{p}^{+}$layer of sample F-16 (F-16.1), where dislocations are shown to be generated, has the highest boron doping $\left(3.7 \times 10^{21} \mathrm{at} / \mathrm{cm}^{3}\right)$, while being neither the thickest nor the thinnest. Rather, the results suggest the existence of a boron concentration threshold value above which dislocations are generated for a given set of growth parameters. We propose to label such value as a critical boron level (CBL). Based on our observations, this parameter seems to depend mainly on some growth conditions, such as $\mathrm{CH}_{4} / \mathrm{H}_{2}$ molar ratio (related to the growth rate), and on the crystallographic orientation. Thus, it is labeled $\mathrm{CBL}_{\left[\mathrm{CH}_{4} / \mathrm{H}_{2}\right] / \text { growth direction }}$.

In order to evaluate the effect of growth conditions and crystallographic orientation, the dislocation density was plotted against the boron concentration of each sample measured by SIMS (Fig. 3). In Fig. 3, samples grown along $\langle 001\rangle$ were represented by circles while growths along $\langle 111\rangle$ were represented by stars. Moreover, those samples grown under the same $\mathrm{CH}_{4} / \mathrm{H}_{2}$ molar ratio and crystallographic orientation are connected by lines. The present study reveals that only four samples contain defects: samples A, C, E, and F-16. In addition, it reveals an abrupt increment of the dislocation density when a specific boron doping level is reached. At the same $\mathrm{CH}_{4} / \mathrm{H}_{2}$ molar ratio $(0.5 \%-0.6 \%)$, the $\mathrm{CBL}$ on $\langle 111\rangle$ is lower than on $\langle 001\rangle$. For this set of samples, $\mathrm{CBL}_{0.6 /\langle 111\rangle}$ and

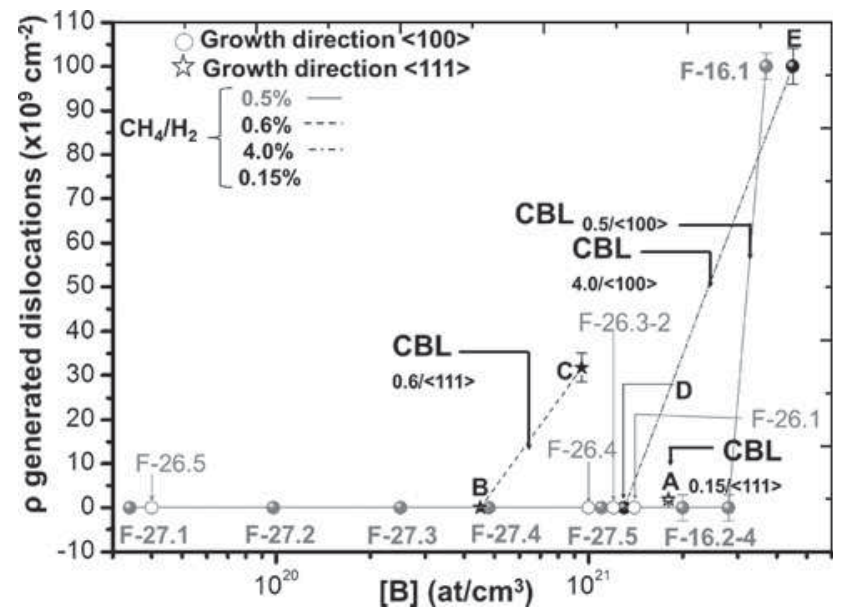

FIG. 3. Density of dislocations as a function of the boron doping level of $\mathrm{p}^{+}$ layers measured by SIMS is plotted. Circles and stars represent samples grown along $\langle 100\rangle$ and $\langle 111\rangle$ direction, respectively. Individual dislocations were not distinguished over $10^{11}$ dislocation $/ \mathrm{cm}^{2}$. 
$\mathrm{CBL}_{0.5 /\langle 100\rangle}$ are estimated at $6.5 \times 10^{20}$ and $3.2 \times 10^{21}$ at/ $\mathrm{cm}^{3}$, respectively, for the present MPCVD conditions. $\mathrm{CBL}_{0.15 /\langle 111\rangle}$ reaches $1.7 \times 10^{21} \mathrm{at} / \mathrm{cm}^{3}$ because sample $\mathrm{A}$ showed a very low dislocation density. Similarly, $\mathrm{CBL}_{4 /\langle 100\rangle}$ is estimated at $2.5 \times 10^{21} \mathrm{at} / \mathrm{cm}^{3}$, which corresponds ${ }^{26}$ to a maximum internal strain of $2 \times 10^{-3}$. Then, for both crystallographic orientations for the diamond substrate, the lower the $\mathrm{CH}_{4} / \mathrm{H}_{2}$ ratio, the larger the $\mathrm{CBL}$.

A possible scenario emerges from these results. At lower $\mathrm{CH}_{4} / \mathrm{H}_{2}$ ratios during diamond growth, the partial pressure of carbon or boron-related molecules is low, and the phase contains less carbon radicals relative to atomic hydrogen, and, in proportion, less boron radicals. Then, the diamond surface is exposed for a long time to highly reactive atomic hydrogen radicals, which are spreading radicals homogeneously over the surface and etching away nondiamond carbon or boron phases. In that case, the growth rate is lower and the probability to form dopant-related point defects such as borondimers ${ }^{32}$ becomes negligible. At higher $\mathrm{CH}_{4} / \mathrm{H}_{2}$ ratios, this spreading becomes less efficient, allowing possible local accumulation of boron atoms. In summary, the lower the $\mathrm{CH}_{4} / \mathrm{H}_{2}$ ratio, the more uniform the boron distribution. In the same way, the difference of CBL measured on $\langle 111\rangle$ and on $\langle 001\rangle$ samples scales with the difference of dangling bonds density at their respective surfaces.

To illustrate the link between boron atoms incorporation and diamond crystalline quality, a schematical representation of a $\langle 111\rangle$-oriented boron-doped diamond lattice is proposed in Fig. 4. If we assume the growing diamond surface to be

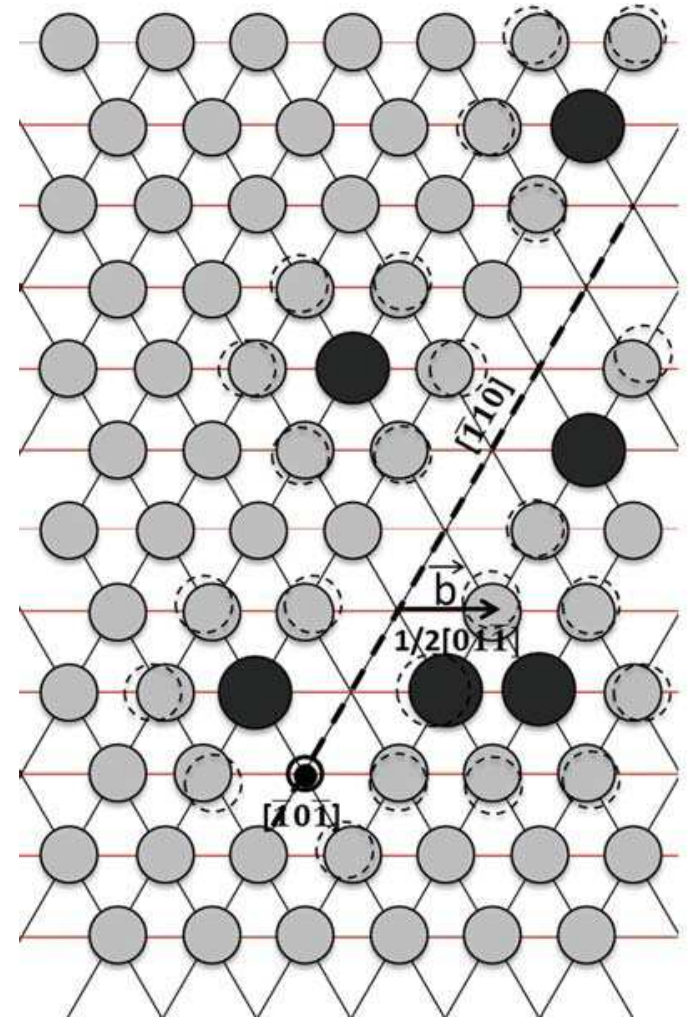

Growth plane

FIG. 4. Schematic views of the dislocation formation on the $(\overline{1} \overline{1} \overline{1})$ growth surface. Dark and light dots correspond to boron and carbon atoms, respectively. The full circle denotes a generation point of dislocation segments due to the propagation of $[\overline{1} 10]$ dislocation (black dashed line). Dashed circles show displacements of carbon atoms from their nominal positions. A black arrow represents a Burger vector $(\vec{b})$ along $1 / 2[011]$. exposed to an instantaneous large amount of boron radicals, then boron aggregates can be formed. Boron atoms have a larger covalent radius than carbon, and their incorporation on substitutional sites induces a strain of the surrounding diamond lattice. ${ }^{38}$ Under our particular conditions, this local strain tends to thrust the top atomic plane upwards, out of its equilibrium position. We surmise that this effect can lead to the formation of planar defects or dislocations (see dashed line in Fig. 4). As shown in this illustration, a random arrangement of boron atoms (dark dots) within the diamond lattice (light dots) in the ( $\overline{1} \overline{1} \overline{1})$ plane of a growing surface, can lead to the formation of a dislocation line (see dashed line) followed by another threading segment. Here, only the displacement of the first neighbor carbon atom (dashed circles) has been considered in order to simplify the picture and to emphasize the dislocation formation. Obviously, this strong neighboring effect should involve a larger number of atoms which move away from their initial atomic positions (even in X-ray topography effects as far as microns are observed) and the resulting displacement is much lower than that showed in this Fig. 4 by the dashed circles. Above a certain local boron concentration, neighboring effects favor the disappearance of an [110] oriented segment of atoms. Moreover, first-principles calculations have shown that pairing of next-neighbor substitutional boron atoms becomes energetically favorable as the Fermi level goes into the valence band upon heavy boron doping. ${ }^{32}$ Such calculations have also evaluated the lattice extension associated with the presence of boron dimers. ${ }^{26}$ We surmise that boron pairs may also contribute to the generation of dislocations. Once such a segment is created, during the growth of the next planes, boron will tend to locate close to this segment, leading to a plane-by-plane replication of the same situation up to the surface. This results is a [110] segment of dislocation with two dislocation segments, one threading aligned along the $[\overline{1} 0 \overline{1}]$ (see full circle) and the other lying in the growing surface plane in the [011] direction. As shown, in this case, the Burger vector of this $2-3$ segments dislocation is $1 / 2[01 \overline{1}]$, in accordance with the invisibility criteria. The second Burger vector that is proposed follows the [112] direction. This direction is perpendicular to the cross-section sample, i.e., its observation would require a TEM micrograph under planar view (PV) configurations. However, this is ill-adapted to most FIB set-ups.

To conclude, heavily boron-doped diamond epilayers grown along $\langle 111\rangle$ and $\langle 001\rangle$ directions were characterized by conventional TEM techniques, and revealed extended defects. Dislocations were generated inside highly boron doped layers grown along the $\langle 111\rangle$ direction at thickness values much lower than predicted by the critical lattice thickness model of Matthews and Blakeslee. The main observed defects were threading dislocations with Burger vectors of $1 / 2[01 \overline{1}]$ or $1 / 6[11 \overline{2}]$. A mechanism involving substitutional boron pairs has been proposed for the generation of dislocations in such epilayers. A critical boron concentration limit (CBL) was shown to trigger the proposed mechanism. The CBL increased when the $\mathrm{CH}_{4} / \mathrm{H}_{2}$ molar ration decreased. It was higher when the growth was made along the $\langle 001\rangle$ direction than for $\langle 111\rangle$-oriented growth. Its value provides an upper bound to the boron doping level of $\mathrm{p}^{+}$epilayers 
increasingly considered for inclusion in the design of diamond-based devices.

We thank to the Ministry of Science and Innovation (MICINN) from The Spanish Government for funding under the Grant No. TEC 2009-11399. We are grateful for the use of the Central Electron Microscopy Facilities of the University of Cádiz and LMA installations. This work was supported in part by Grant No. 1101543301 under CMIRA program of Région Rhône-Alpes.

${ }^{1}$ R. Long, Y. Dai, M. Guo, L. Yu, B. Huang, R. Zhang, and W. Zhang, Diamond Relat. Mater. 17, 234 (2008).

${ }^{2} \mathrm{M}$. Stoneham, in Physic and Application of CVD Diamond, edited by S. Koizumi, C. Nebel, and M. Nesladek (Wiley-VCH, Weinheim, 2008).

${ }^{3}$ A. Crisci, F. Baillet, M. Mermoux, G. Bogdan, M. Nesladek, and K. Haenen, Phys. Status Solidi A 208, 2038 (2011).

${ }^{4}$ Y. Kato, H. Umezawa, H. Yamaguchi, and S. Shikata, Diamond Relat. Mater. 29, 37 (2012).

${ }^{5}$ C. Fernández-Lorenzo, D. Araújo, M. González-Mañas, J. Martín, J. Navas, R. Alcántara, M. P. Villar, and D. Bagriantsev, J. Cryst. Growth 353, 115 (2012).

${ }^{6}$ A. Mussi, D. Eyidi, A. Shiryaev, and J. Rabier, Phys. Status Solidi A 210, 191 (2013).

${ }^{7}$ P. Martineau, M. Gaukroger, R. Khan, and D. Evans, Phys. Status Solidi C 6, 1953 (2009)

${ }^{8}$ U. Bangert and R. Barnes, Phys. Status Solidi A 204, 2201 (2007).

${ }^{9}$ R. Barnes, U. Bangert, and P. Martineau, Phys. Status Solidi A 203, 3081 (2006)

${ }^{10}$ H. Sawada, H. Ichinose, H. Watanabe, D. Takeuchi, and H. Okushi, Diamond Relat. Mater. 10, 2030 (2001).

${ }^{11}$ M. Tarutani, Y. Takai, R. Shimizu, T. Ando, M. Kamo, and Y. Bando, Appl. Phys. Lett. 68, 2070 (1996).

${ }^{12}$ F. Langenhorst, J. P. Poirier, and D. J. Frost, J. Mater. Sci. 39, 1865 (2004).

${ }^{13}$ J. Pernot, P. N. Volpe, F. Omnès, P. Muret, V. Mortet, K. Haenen, and T. Teraji, Phys. Rev. B 81, 205203 (2010).

${ }^{14}$ J. Pernot, C. Tavares, E. Gheeraert, E. Bustarret, M. Katagiri, and S. Koizumi, Appl. Phys. Lett. 89(12), 122111 (2006).

${ }^{15}$ R. S. Balmer, I. Friel, S. M. Woollard, C. J. H. Wort, G. A. Scarsbrook, S. E. Coe, H. El-Hajj, A. Kaiser, A. Denisenko, E. Kohn, and J. Isberg, Philos. Trans. R. Soc. A 366, 251 (2008).

${ }^{16}$ T. Klein, P. Achatz, J. Kacmarcik, C. Marcenat, F. Gustafsson, J. Marcus, E. Bustarret, J. Pernot, F. Omnès, B. E. Sernelius, C. Persson, A. Ferreira da Silva, and C. Cytermann, Phys. Rev. B 75, 165313 (2007).
${ }^{17}$ A. Traoré, P. Muret, A. Fiori, D. Eon, E. Gheeraert, and J. Pernot, Appl. Phys. Lett. 104, 052105 (2014).

${ }^{18}$ I. A. Prokhorov, V. G. Ralchenko, A. P. Bolshakov, A. V. Polskiy, A. V. Vlasov, I. A. Subbotin, K. M. Podurets, E. M. Pashaev, and E. A. Sozontov, Crystallogr. Rep. 58, 1010 (2013).

${ }^{19}$ D. Araújo, E. Bustarret, A. Tajani, P. Achatz, M. Gutiérrez, A. J. García, and M. P. Villar, Phys. Status Solidi A 207, 2023 (2010).

${ }^{20}$ S. Kitagoh, R. Okada, A. Kawano, M. Watanabe, Y. Takano, T. Yamaguchi, T. Chikyow, and H. Kawarada, Phys. C 470, S610 (2010).

${ }^{21}$ A. Fiori, T. N. T. Thi, G. Chicot, F. Jomard, F. Omnès, E. Gheeraert, and E. Bustarret, Diamond Relat. Mater. 24, 175 (2012).

${ }^{22}$ L. Repetto, G. Firpo, and U. Valbusa, Mater. Tehnol. 42(4), 143 (2008).

${ }^{23}$ P. Olivero, S. Rubanov, P. Reichart, B. C. Gibson, S. T. Huntington, J. Rabeau, A. D. Greentree, J. Salzman, D. Moore, D. N. Jamieso, and S. Prawer, Adv. Mater. 17(20), 2427 (2005).

${ }^{24}$ D. Araújo, D. González, R. García, A. Sacedón, and E. Calleja, Appl. Phys. Lett. 67, 3632 (1995).

${ }^{25}$ A. Kawano, H. Ishiwata, S. Iriyama, R. Okada, T. Yamaguchi, Y. Takano, and H. Kawarada, Phys. Rev. B 82, 085318 (2010).

${ }^{26}$ T. Wojewoda, P. Achatz, L. Ortéga, F. Omnès, C. Marcenat, E. Bourgeois, X. Blase, F. Jomard, and E. Bustarret, Diamond Relat. Mater. 17, 1302 (2008).

${ }^{27}$ V. V. Brazhkin, E. A. Ekimov, A. G. Lyapin, S. V. Popova, A. V. Rakhmanina, S. M. Stishov, V. M. Lebedev, Y. Katayama, and K. Kato, Phys. Rev. B 74, 140502(R) (2006).

${ }^{28}$ F. Brunet, P. Germi, M. Pernet, A. Deneuville, E. Gheeraert, F. Laugier, M. Burdin, and G. Rolland, Diamond Relat. Mater. 7, 869-873 (1998).

${ }^{29}$ Landolt-Börnsteim, in Numerical Data and Functional Relationships in Science and Technology (Springer-Verlag, Berlin, 1982), Vol. III.

${ }^{30}$ E. Bustarret, E. Gheeraert, and K. Watanabe, Phys. Status Solidi A 199, 9-18 (2003).

${ }^{31}$ E. Bustarret, P. Achatz, B. Sacepe, C. Chapelier, C. Marcenat, L. Ortega, and T. Klein, Philos. Trans. R. Soc. A 366, 267-269 (2008).

${ }^{32}$ E. Bourgeois, E. Bustarret, P. Achatz, F. Omnès, and X. Blase, Phys. Rev. B 74, 094509 (2006).

${ }^{33}$ J. W. Matthews and A. E. Blakeslee, J. Cryst. Growth 27, 118 (1974).

${ }^{34}$ A. Sacedón, F. González-Sanz, E. Calleja, E. Muñoz, S. I. Molina, F. J. Pacheco, D. Araújo, R. García, M. Lourenço, Z. Yang, P. Kidd, and D. Dunstan, Appl. Phys. Lett. 66, 3334 (1995).

${ }^{35}$ D. Araújo, A. Tajani, E. Gheeraert, and E. Bustarret, J. Phys. Condens. Matter. 16, S287 (2004).

${ }^{36}$ D. Araújo, M. P. Alegre, J. C. Piñero, A. Fiori, E. Bustarret, and F. Jomard, Appl. Phys. Lett. 103, 042104 (2013).

${ }^{37}$ P. Achatz, F. Omnès, L. Ortéga, C. Marcenat, J. Vacík, W. Hnatowicz, U. Koster, F. Jomard, and E. Bustarret, Diamond Relat. Mater. 19, 814-817 (2010).

${ }^{38}$ E. Bustarret, Phys. Status Solidi A 205, 997 (2008). 